\title{
Households' Risk Perception and Behavioral Responses to Natech Accidents
}

\author{
Junlei $\mathrm{Yu}^{1} \cdot$ Ana Maria $\mathrm{Cruz}^{2} \cdot$ Akihiko Hokugo $^{3}$
}

Published online: 27 March 2017

(C) The Author(s) 2017. This article is an open access publication

\begin{abstract}
This study analyzes data on households' risk perception and protective behavior following a natural disaster triggered technological accident (Natech accident) that occurred at an industrial park in Sendai during the Great East Japan Earthquake and Tsunami, on 11 March 2011. The results indicate that some households carried out multiple evacuations and that households' risk perceptions changed throughout the Natech accident evacuation process. Risk perception differed according to household location and demographic characteristics. We also found differences in the protective measures adopted for households in different locations. Specifically, those living closer to the Natech accident tended to evacuate immediately, whereas those living further away tended to shelter in place. Wind direction is discussed as a factor that influences households' risk perception and evacuation response to a Natech accident. The findings of this study advance knowledge of household behavior in response to a Natech accident and can assist emergency managers in developing strategies for better management of evacuation processes.
\end{abstract}

Keywords Evacuation behavior - Great East Japan Earthquake and Tsunami $\cdot$ Natech accidents - Protective actions $\cdot$ Risk perception

Junlei Yu

junleiyu2013@gmail.com

1 School of Humanities and Social Science, Nanyang Technological University, Singapore 637332, Singapore

2 Disaster Prevention Research Institute, Kyoto University, Kyoto 611-0011, Japan

3 Research Center for Urban Safety and Security, Kobe University, Kobe 657-8501, Japan

\section{Introduction}

A natural disaster triggered technological accident (Natech accident) was first defined by Showalter and Myers (1992) when they reviewed the causes of chemical accidents triggered by natural hazard events. Natechs triggered by several natural hazards have been studied including by earthquakes (Lindell and Perry 1997), hurricanes (Cruz and Krausmann 2008), floods (Cozzani et al. 2010), lightening (Krausmann et al. 2011), and tsunami (Krausmann and Cruz 2013). Natech accidents, which make up about $3 \%$ of all reported hazmat releases between 1990 and 2008 in the United States, were reported as the cause of a small fraction of human impacts in the country (Sengul et al. 2012). In the European Union, Krausmann and Baranzini (2012) have also studied and reported on Natech accidents. It is expected that climate change and the presence of increased populations in areas subject to high risk from natural hazards may result in greater human impacts from Natech accidents in the future.

Natech accidents often occur over extensive geographical areas due to the large impact zone of natural hazard events (Seteinberg et al. 2008). Natech accidents are often accompanied by fires, explosions, and/or toxic releases. The areas that could be affected by such hazards may also expand at any time through cascading chemical accidents and effects if Natech accident cannot be controlled in an effective and timely manner. Thus, large numbers of residents in a relatively large area may need to take protective actions (for example, evacuation, shelter in place). However, in the context of a Natech accident, people have to face at least two hazards within a limited time. The Natech accident that occurred during the Great East Japan Earthquake and Tsunami on 11 March 2011 is a good example. Many residents living near an affected industrial park in 
Sendai initially evacuated due to the earthquake and/or tsunami. With the retreat of the tsunami, some evacuees left the evacuation shelters and returned home. Then, following the occurrence of a Natech accident at a nearby refinery $5 \mathrm{~h}$ later, residents were confronted with the decision to evacuate again or not, based on their own risk perceptions of the threat posed by the huge fires and smoke coming from the accident.

This study presents the results of a random household survey on risk perceptions and behavioral responses following a Natech accident at the oil refinery in Sendai, Japan after the 2011 earthquake and tsunami. The authors specifically address four questions:

1. How did household Natech accident risk perception change throughout the evacuation process?

2. What protective actions did households take in response to the Natech accident?

3. What differences are there in risk perceptions and protective behavior according to household location?

4. Which groups had higher risk perception levels and were more likely to adopt protective measures?

\section{Literature Review}

Risk perception has been found to be a key factor in motivating protective actions such as evacuation behavior (Baker 1991; Fitzpatrick and Mileti 1991; Sorensen 1991, 2000; Riad et al. 1999; Mileti and Peek 2000; Tierney et al. 2001; Dash and Gladwin 2007; Sorensen and Sorensen 2007; Lindell 2012, 2013; Lindell and Prater 2012). Baker (1991) reviewed more than 12 sample surveys on hurricane evacuation in the United States from 1961 to 1989 . Prior perception of personal risk, the risk level (hazardousness) commonly associated with an area, action by public authorities, housing protective quality, and storm-specific threat factors were found to largely account for evacuation behavior. The author found that residents who felt unsafe staying where they were (perceived consequences) during a storm tended to leave, and those who felt safe (no perceived consequences) tended to stay. Riad et al. (1999) analyzed why people sometimes decide not to evacuate from a dangerous situation based on a resident interview survey after Hurricanes Hugo and Andrew. They found that not perceiving the hurricane as a threat and believing one's home was a safe place were the most common reasons for not evacuating.

The above studies examined risk perception and protective actions during hurricanes. Only a few studies have analyzed risk perception of and protective actions to technological threats. Mileti and Peek (2000) reviewed the process of forming perceptions and how this process affects public response to warnings of a nuclear power plant emergency. The authors found that the formation of risk perception is guided by the stimulations, cues, and so on that people secure from their environment (for example, warning information), and that this risk perception formation leads to protective actions. This process is not different than that found for other types of hazard agents (Mileti and Peek 2000). Risk perception leading to protective actions was also confirmed by a study that analyzed evacuation behavior in response to a chlorine spill at Graniteville, South Carolina, in 2005 (Mitchell et al. 2005).

The potential influence of risk perception on people's response to Natech accidents has been limited. Indeed, only a few studies have attempted to address this issue. In a counter-factual study, Steinberg et al. (2004) examined emergency preparedness and earthquake hazard mitigation for the potential impact of an earthquake-induced hazardous materials release from an oil refinery in a southern California community based on a random telephone survey. The authors also investigated residents' risk perception to Natech hazard events. They found a nonsignificant relationship between risk perception and preparedness and mitigation. Perceived risk and corresponding actions may differ when people actually experience a Natech accident in real life (Steinberg et al. 2004). This article provides insights on risk perception and the consequent protective actions taken during an actual Natech event, the fires at the Sendai industrial park triggered by the 2011 earthquake and tsunami.

Many factors have been studied to understand their influence on risk perception and evacuation behavior. Relationships between risk perception and proximity to hazards have been discussed for hurricanes (Peacock et al. 2005), floods (Siebeneck and Cova 2012), earthquakes (Lindell and Perry 2000), and hazards resulting from hazardous industrial facilities (Lindell and Earle 1983). A recent study examined how risk perception changed with time throughout an evacuation process and found higher risk perception levels occurred while evacuees were staying at evacuation shelters (Siebeneck and Cova 2012). In another study, Lin et al. (2014) examined risk perception changes of evacuees during Hurricane Ike. They found that households believed that their homes were much more dangerous when the storm made landfall (Lin et al. 2014). Zelinsky and Kisinski (1991) pointed out that the distancedecay principle generally applies to the movement of evacuees in evacuations for both natural and technological disasters (Zelinski and Kisinski 1991). The authors also reported that evacuation direction is unpredictable unless the physical impact of the disaster is directional in nature. Home elevation was found to be an important hurricane evacuation predictor (Baker 1991). 
Demographic variables have also been examined in several studies on risk perception and evacuation behavior. However, most demographic variables (other than gender) have weak and inconsistent correlations with risk perception and protective responses (Baker 1991; Lindell and Perry 2000; Lindell 2013). Stern et al. (1993) found that females are associated with higher risk perception levels than are males. The authors explain that women are more aware than men of the consequences of events; therefore women are more likely to develop beliefs about the consequences of hazardous situations. Several studies have found that women were more likely to evacuate for hurricanes (Bateman and Edwards 2002; Lindell et al. 2005; Huang et al. 2012), and they were also more likely to respond to earthquake aftershocks (Mileti and O'Brien 1992) and hurricane warnings (Bateman and Edwards 2002). But a recent flood evacuation survey of three communities in Hat Yai, Thailand, found that men were more likely to evacuate than women (Luathep et al. 2013). The authors also reported that the households with a larger number of children or elderly persons were less likely to evacuate. Thus, it is highly possible that many women stayed to take care of children and elderly persons. Huang et al. (2012), who observed that being older correlated with a lower risk perception for hurricanes, explained that older people tended to expect less personal impact (Huang et al. 2012). In contrast, age was reported positively correlated with the risk perception of coastal flood risks (Kellens et al. 2011).

Age is also an inconsistent contributor for protective actions. Older people were found to be less likely to evacuate for floods (Luathep et al. 2013) or to respond to earthquake aftershock warnings (Mileti and O'Brien 1992); but other studies have found that there were no correlations between age and hurricane evacuation (Baker 1991). Other variables were also discussed. For example, family size (household size) was found to have a negative, but not significant, correlation with evacuation from hurricanes in Florida (Solis et al. 2009), and no consistent evidence was found for the notion that people's evacuation behavior depends on how long they had lived in the coastal area (Baker 1991). These inconsistent results increased interest in examining the role demographic variables play in affecting people's risk perception and protective actions to Natech accidents. Furthermore, in the context of a Natech accident, the risk perception changes may be different, because multiple evacuations may be involved.

\section{Event Description}

A 9.0 magnitude earthquake struck off the Pacific coast of the Tohoku area (Northeast Japan), on 11 March 2011 at 14:46 (local time). This quake was registered as the most powerful earthquake in the history of Japan (Mimura et al. 2011), and the fourth most intense ever recorded in the world (USGS 2014). The earthquake triggered a tsunami with run-up heights in excess of $39 \mathrm{~m}$, which resulted in 15,889 people dead and 2594 missing (NPA 2014). According to the report by the Ministry of Land, Infrastructure, Transport and Tourism of Japan (MLITT 2014), about $535 \mathrm{~km}^{2}$ of coastal lowlands were inundated totally or partially, destroying 220,000 buildings. Moreover, the earthquake and tsunami caused damage to oil storage tanks and other hazardous materials facilities in petrochemical industrial complexes. Nishi (2012) reported that 1404 hazmat facilities were damaged by the earthquake's strong ground motion and 1807 hazmat facilities were damaged by the tsunami. A major Natech accident occurred at an oil refinery in an industrial park near Sendai, resulting in severe consequences for nearby residents. The tsunami resulted in several evacuation warnings, the first being given just minutes after the main earthquake shock. In addition, the Natech accident forced local officials to order an evacuation of residents in a $2 \mathrm{~km}$ radius around the refinery (Yamagochi 2012), which included several tsunami evacuation shelters.

The Sendai refinery is large, occupying $1.5 \mathrm{~km}^{2}$, and is physically located across three different jurisdictions: Tagajo city, Shichigahama town, and Sendai city. The location and layout of the refinery is presented in Fig. 1. At $21: 25$ on the day of the earthquake, fires broke out at the eastern part of the refinery in the industrial complex in Sendai (Yamagochi 2012). The fires occurred at the refinery's asphalt tanks, a gasoline tank, several molten sulfur tanks, and a shipping yard (Nishi 2012). The cause of fires was unknown, but Zama et al. (2012) believed that a floating oil spill was ignited due to a spark caused by the collision between tank lorries and oil handling facilities during the tsunami.

As indicated in Table 1, a big tsunami warning was issued at 15:15 on the day of the earthquake. Fifteen minutes after receiving the big tsunami warning, refinery staff began to walk to a primary school (evacuation shelter) located in Shichigahama town about $2 \mathrm{~km}$ away. When the fire broke out at 21:25, the evacuated staff made a request to the local officials to issue an evacuation order for residents living near the refinery. Given the difficulties with communication systems and the ongoing tsunami warning, the Shichigahama authorities issued an evacuation order in the morning of the next day (9:25 on March 12). About $1 \mathrm{~h}$ later, Tagajo city also issued an evacuation order (10:16 on March 12). Sendai city was the last to issue evacuation orders at 7:30 on March 13. The fires were extinguished by 14:30 on March 15 (Yamagochi 2012), and all evacuation orders were canceled at 15:00 on March 15 (Shichigahama 2012; Tagajo 2012). 


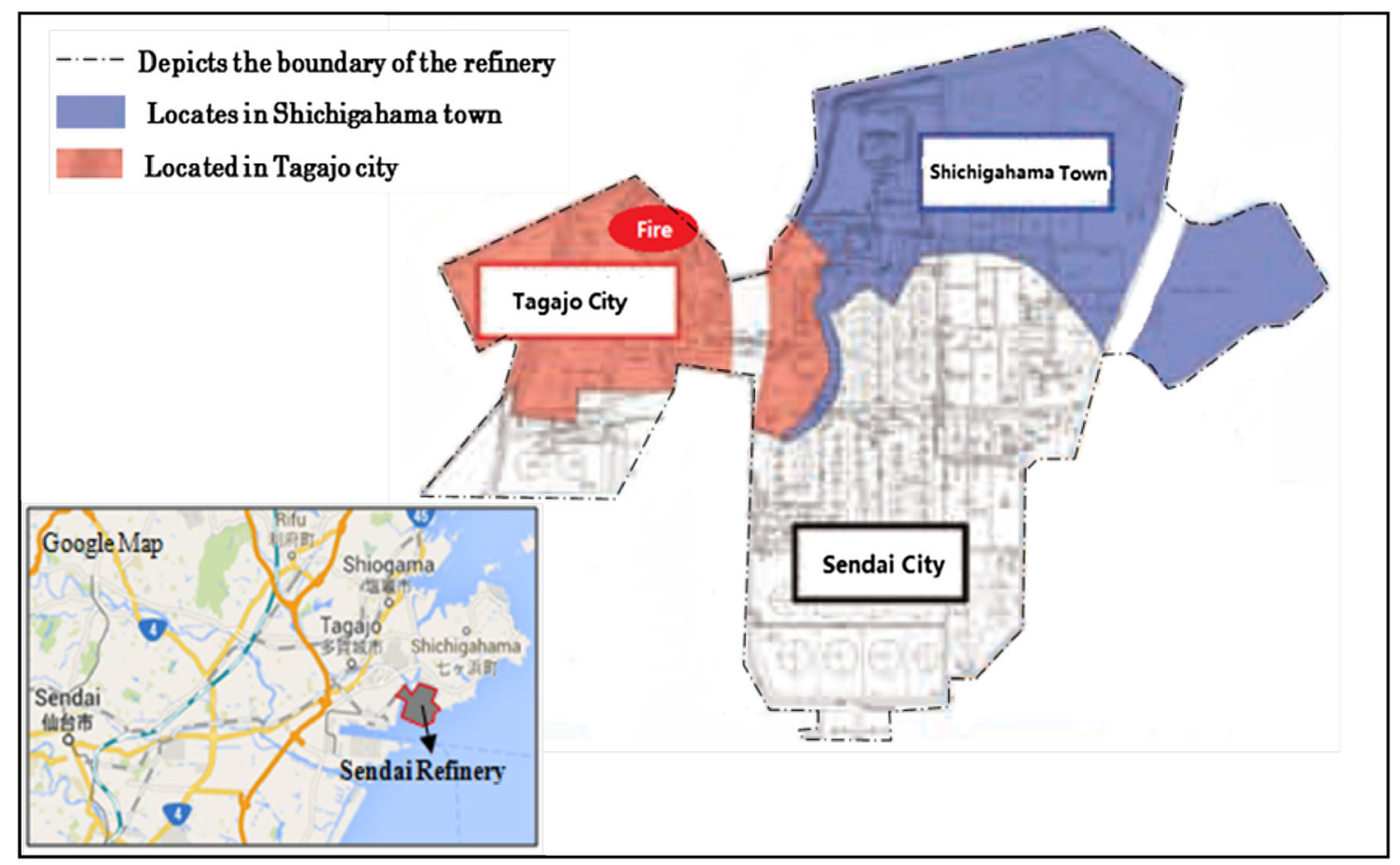

Fig. 1 Location and layout of Sendai refinery. Source Base map Yamagochi (2012)

Table 1 Event time line. Source Shichigahama (2012), Tagajo (2012) and Yamagochi (2012)

\begin{tabular}{lll}
\hline Date & Time & Event \\
\hline 3.11 & $02: 46 \mathrm{p} . \mathrm{m}$. & Earthquake \\
& $03: 15 \mathrm{p} . \mathrm{m}$. & Big tsunami warning \\
& $03: 30 \mathrm{p} . \mathrm{m}$. & Refinery staff began to evacuate to the shelter at Shichigahama town \\
& $03: 50 \mathrm{p} . \mathrm{m}$. & Tsunami arrived \\
& $05: 10 \mathrm{p} . \mathrm{m}$. & Observed black smoke from the refinery \\
& $05: 25 \mathrm{p} . \mathrm{m}$. & Big fire broke out \\
& $09: 30 \mathrm{p} . \mathrm{m}$. & Refinery staffs requested Shichigahama town to evacuate residents \\
3.12 & $9: 25 \mathrm{a} . \mathrm{m}$. & Shichigahama town issued evacuation order \\
& $10: 26 \mathrm{a} . \mathrm{m}$. & Tagajo city issued evacuation order \\
3.13 & $07: 30 \mathrm{a} . \mathrm{m}$. & Sendai city issued evacuation order \\
3.15 & $02: 30 \mathrm{p} . \mathrm{m}$. & Fire extinguished \\
\hline
\end{tabular}

\section{Methodology}

In this study, data collection involved two person-to-person field surveys and one mail survey in order to understand residents' attitudes and protective actions such as evacuation due to Natech accidents. We were also interested in collecting information concerning damage caused by the 2011 Natech accident and the evacuation order issuing process. The first person-to-person survey was conducted on 10 November 2013. Thirteen residents living within $3 \mathrm{~km}$ of the affected refinery were randomly selected and interviewed. The second person-to-person survey, supported by the ResTO-TerRiN Project, ${ }^{1}$ was carried out from 17 to 20 March 2014. During the investigation, we interviewed the personnel at the refinery as well as disaster management officers who experienced or were in charge of investigating the Natech accidents triggered by the Great East Japan Earthquake and Tsunami.

\footnotetext{
${ }^{1}$ ResTO-TerRiN Project: French Ministry of Ecology, Sustainable Development and Energy (MEDDE) funded project, entitled Contribution to the Systemic Modeling of Technical and Organizational Resilience of a Territory to Natech Risk: from microscopic to macroscopic (2013-2016).
} 


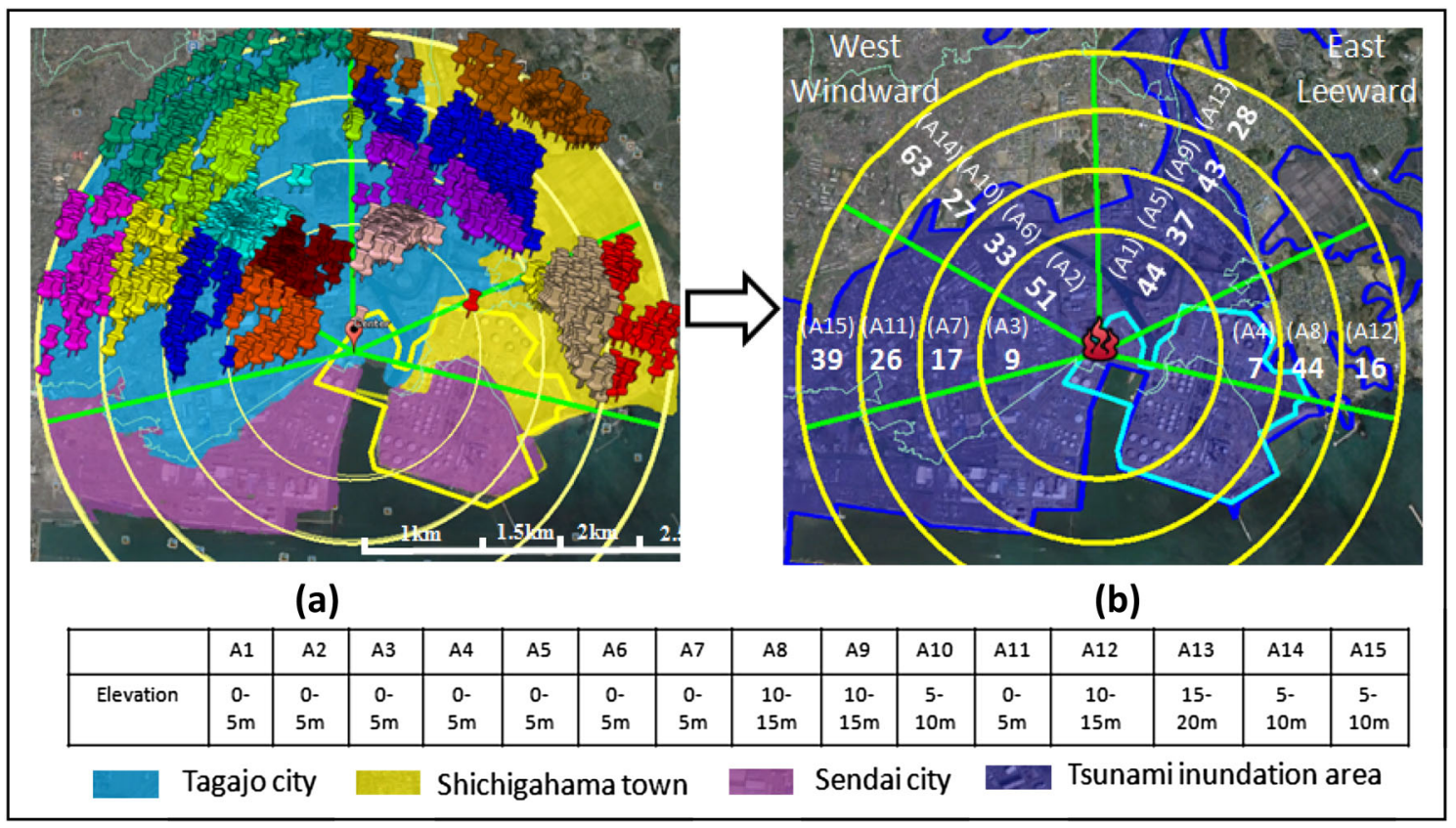

Fig. 2 Distribution of a sampled households showed with pins in colors and $\mathbf{b}$ returned questionnaires in the 15 areas sampled including the range of the elevation above sea level for each area (A1-A15)

A household survey questionnaire was developed in order to study risk perception and behavioral responses to the Natech accident, taking into consideration the research questions, past literature, and person-to-person interviews. We used the Zenrin Co., $\mathrm{Ltd}^{2}$ detailed address database as a sampling frame. A random sample of households living within an area of $2.5 \mathrm{~km}$ from the hazard source was taken. The questionnaires were sent out on 31 March 2014, indicating a due date on 25 May 2014.

Based on our interviews with refinery officials, the primary hazard source was liquefied petroleum gas (LPG) tanks in the tank farm that was located close to the fire site. Although the fires did not start at the LPG tanks, these represented the main threat to residents if the fire spread and caused these LPG tanks to explode. Respondents were selected from households at increments of $0.5 \mathrm{~km}$ from 1 to $2.5 \mathrm{~km}$ from the center of the LPG tank farm to the residential area. A disproportionate stratified sampling technique was utilized. The area was divided according to distance and direction from the Natech accident as shown in Fig. 2a. Four hundred respondents were sampled from each area for a total number of 1732 respondents. About 1 month later, a second mailing was sent to nonrespondents after addresses were checked. A total of 1632 questionnaires were effectively delivered

\footnotetext{
2 Zenrin Company. Address index database. Available at http://www. zenrin.co.jp/english/index.html (updated Aug, 24, 2012, bought Apr, 2014)
}

and 484 households responded, for a response rate of $29.4 \%$. Figure 2 presents the distribution of (a) sampled households and (b) returned questionnaires in 15 areas. The figure also shows a range in elevation above sea level for each area (A1-A15). In order to protect privacy, we labeled each questionnaire with distance and direction to the industrial park only, instead of asking respondents to provide their detailed addresses or making any marks on questionnaire sheets. Thus, we only have the number of respondents from each of these areas.

The questionnaire was composed of 14 pages with questions about respondents' evacuation and reentry experiences regarding the Natech accidents during the earthquake and tsunami. Results regarding the evacuees' risk perception and protective behavior response are discussed in this article. Of the 484 respondents, the average age was 61 , and $55.8 \%$ were men. The majority were house owners with no evacuation or training experiences with Natech accidents. Households with couples and two generations answered 36.2 and $36.6 \%$ of the questionnaires, respectively. The length of residence extends from less than 10 years to more than 40 years. The results are summarized in Table 2. Comparison of the sample's demographic characteristics to the 2010 Census data of Japan suggests that, with exception of an overrepresentation of respondents who were homeowners and from larger households, the sample is relatively representative of the whole population. 
Table 2 Demographic statistics for respondents

\begin{tabular}{|c|c|c|c|c|c|}
\hline \multicolumn{3}{|l|}{ Gender } & \multicolumn{3}{|c|}{ House ownership } \\
\hline Male & Female & No answer & Yes & No & No answer \\
\hline $55.8 \%$ & $38.2 \%$ & $6.0 \%$ & $89.7 \%$ & $5.5 \%$ & $4.8 \%$ \\
\hline \multicolumn{3}{|c|}{ Natech accident evacuation experience } & \multicolumn{3}{|c|}{ Natech accident training experience } \\
\hline Yes & No & No answer & Yes & No & No answer \\
\hline $1.2 \%$ & $92.4 \%$ & $6.4 \%$ & $12.0 \%$ & $84.5 \%$ & $3.5 \%$ \\
\hline \multicolumn{6}{|c|}{ Household size } \\
\hline Single & Couple & 2 generations & 3 generations & $>3$ generations & No answer \\
\hline $6.4 \%$ & $36.2 \%$ & $36.6 \%$ & $13.2 \%$ & $5.1 \%$ & $2.5 \%$ \\
\hline \multicolumn{6}{|c|}{ Residency length } \\
\hline$\leq 10$ years & $>10 \leq 20$ years & $>20 \leq 30$ years & $>30 \leq 40$ years & $>40$ years & No answer \\
\hline $17.2 \%$ & $19.6 \%$ & $19.8 \%$ & $16.7 \%$ & $20.7 \%$ & $6.0 \%$ \\
\hline
\end{tabular}

Fig. 3 The number of respondents during the multiple evacuations and the reasons for evacuating

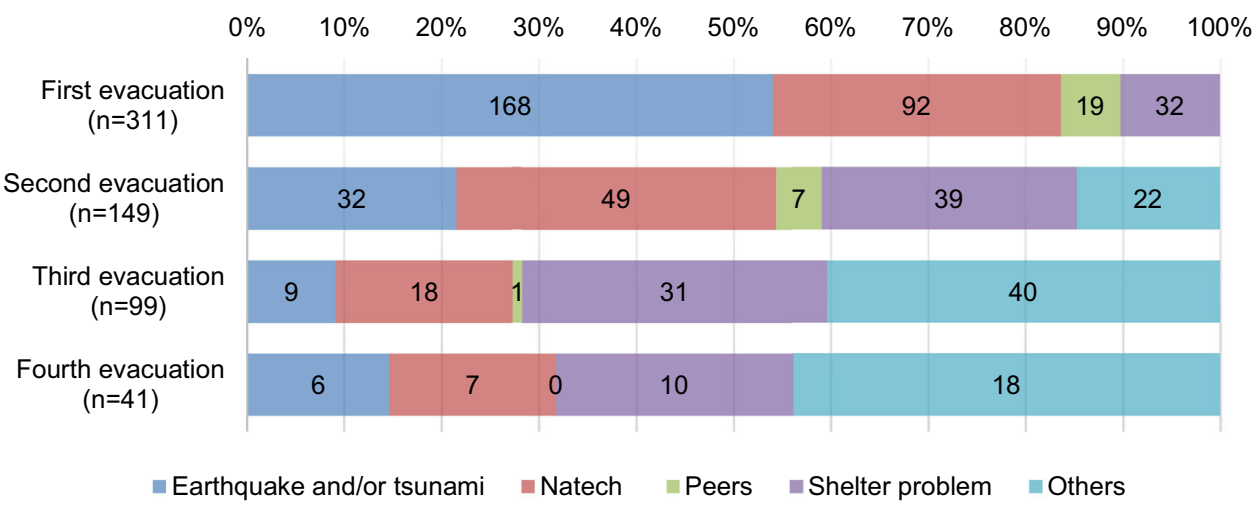

\section{Results}

Of the 484 respondents, $311(64.3 \%)$ evacuated at least once, 149 (30.8\%) evacuated twice, 99 (20.5\%) evacuated three times, and $41(8.5 \%)$ evacuated four times. Furthermore, 153 out of $484(31.6 \%)$ respondents indicated they did not evacuate, and $20(4 \%)$ of them did not respond to this question. Households evacuated more than once because of the multiple hazards they encountered or other reasons. Respondents were asked to indicate the reasons for each evacuation by providing a list of multiple options. A total of $179(37.0 \%)$ respondents said they evacuated due to the earthquake and/or tsunami at least once. Similarly, 128 (26.4\%) respondents said they evacuated due to the Natech accident at least once. As indicated in Fig. 3, for the first evacuation, 168 out of 311 evacuees evacuated because of the earthquake and tsunami (54.0\%), and 92 (29.6\%) of them evacuated for the Natech accident. The number of respondents that indicated that they evacuated a second time due to the earthquake/tsunami decreased substantially (21.5\%). Instead, $32.9 \%$ of respondents indicated that they evacuated a second time for the Natech accident, and $26.2 \%$ of respondents evacuated a second time due to shelter problems such as a shelter was too crowed or lacked necessities for family members with special needs. During the third and fourth evacuations, the natural disaster and Natech accident were not the primary reasons for evacuating. In addition to indicating shelter problems, some respondents said they were rescued by the Japanese Ground Self-Defense Force ${ }^{3}$ or picked up by other family members. Very few respondents indicated that they evacuated because of seeing others' actions (peers).

\footnotetext{
3 The Japan Ground Self-Defense Forces (自衛隊 Jieitai) are the military forces of Japan and controlled by the Ministry of Defense. They conducted emergency response and search and rescue following the Great East Japan Earthquake and Tsunami of 2011.
} 


\subsection{Changes of Risk Perceptions}

We used likelihood and severity to measure the risk perception levels by asking: how likely do you think a Natech accident would be a threat to your life or property: 1 (very unlikely) to 5 (very likely) before the quake, just after the earthquake shaking, and in the next 10 years. Furthermore, we asked to what extent households felt that a Natech accident would affect their lives or property: 1 (small extent) to 4 (very great extent) before the quake, just after the earthquake shaking, when they perceived the occurrence of the Natech accident, when they received the Natech accident evacuation order, while staying at the evacuation shelters, and in the next 10 years. One-way repeated measures ANOVA tests were conducted to determine if household risk perception levels changed significantly during the Natech accident. The results show that households' risk perception in terms of the perceived likelihood that a Natech would cause harm to their lives or property before the quake, just after the earthquake shaking, and in the next 10 years were significantly different, $F$ $(1.70,591.20)=25.05, p<0.001$, with GreenhouseGeisser correction. Notably, as indicated in Fig. 4, as expected, household's risk perception in terms of the perceived likelihood increased after experiencing the Natech during the quake, $t(368)=-6.81, p<0.001$.

The effect of time periods on household risk perception in terms of perceived Natech severity was not significant

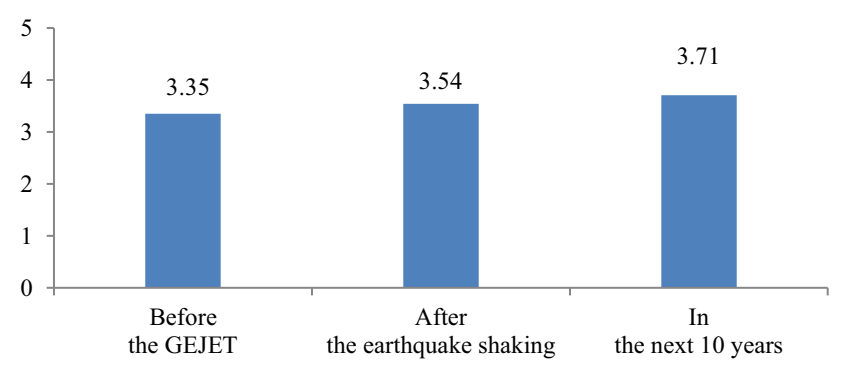

Fig. 4 Mean risk likelihood rating for Natech
(Wilks' $\Lambda=0.21, F(6,4)=2.45, p=0.20$, MANOVA). As presented in Fig. 5, no change was found in risk perception in terms of the perceived severity of the impacts of a Natech accident when compared with their responses before the Great East Japan Earthquake and Tsunami and in the next 10 years. This may be due to the fact that no deaths, injuries, or severe environmental damage due to the Natech was reported. In addition, we found that households felt that the Natech would affect their lives to a great extent ( score $=3$ ) and to a very great extent $($ score $=4)$ in four time periods: when they perceived its occurrence ( $M=3.48 \pm 0.75)$; while they were staying at the first/ second evacuation shelter $(M=3.49 \pm 0.74$, $M=3.44 \pm 0.82)$; and when they received the Natech evacuation order $(M=3.55 \pm 0.70)$.

Tests were conducted to determine if a significant relationship exists between respondents' geographic locations and risk perception in four time periods. As Fig. 6 shows, risk perceptions decreased with distance to the Natech hazard in all time periods except when respondents received the Natech evacuation order. One-between-onewithin ANOVA tests were conducted with distance to the Natech hazard $(\leq 1 \mathrm{~km},>1 \mathrm{~km}$ and $\leq 1.5 \mathrm{~km},>1.5 \mathrm{~km}$ and $\leq 2 \mathrm{~km}$, and $>2 \mathrm{~km}$ and $\leq 2.5 \mathrm{~km})$ as between-subjects and four time periods (before the quake, just after the earthquake shaking, when respondents perceived the Natech occurrence, and when they received the Natech evacuation order) as the within-subjects variables. The main effect of between-subjects variables shows that respondents' risk perceptions in terms of likelihood (before the quake and just after the earthquake shaking) were significantly different according to their distance to the Natech accident ( $F$ $\left.(3,441)=5.94, p=0.01, \eta^{2}=0.04\right)$. However, the effect of distance on risk perception in terms of severity (during the four examined time periods) was not significant $(F(3$, 139) $\left.=1.04, p=0.38, \eta^{2}=0.02\right)$.

Furthermore, we examined the change in risk perception with the range of the elevation of the area of each household surveyed and its location direction with respect to the
Fig. 5 Mean risk severity ratings for Natech throughout the evacuation process

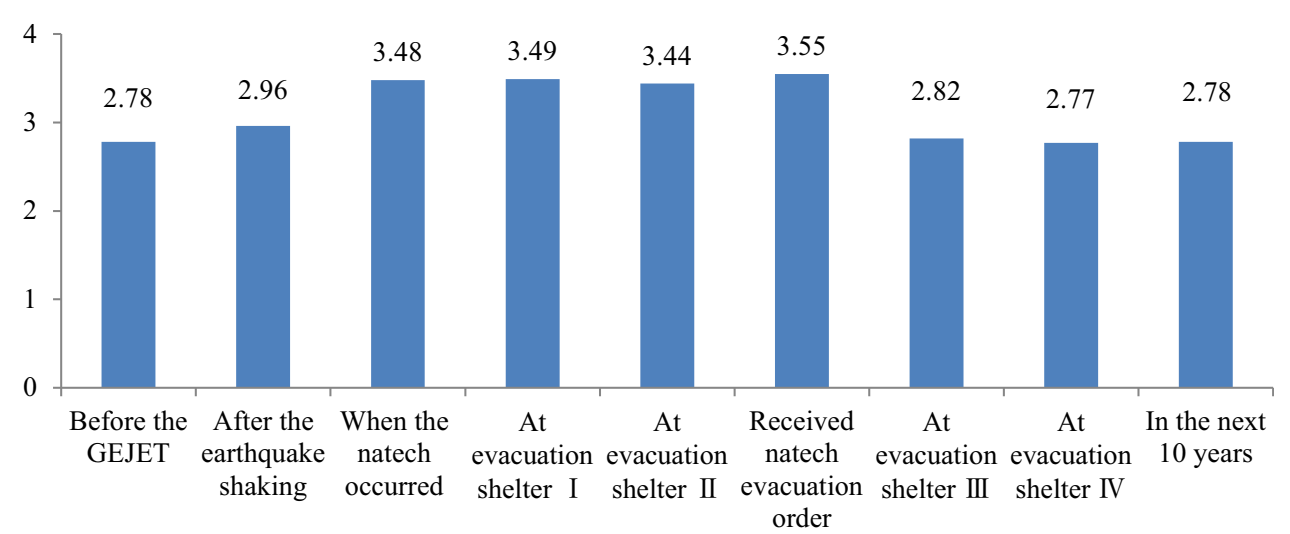


Fig. 6 Mean perceived risk by distance

Fig. 7 Mean perceived risk by location direction and elevation
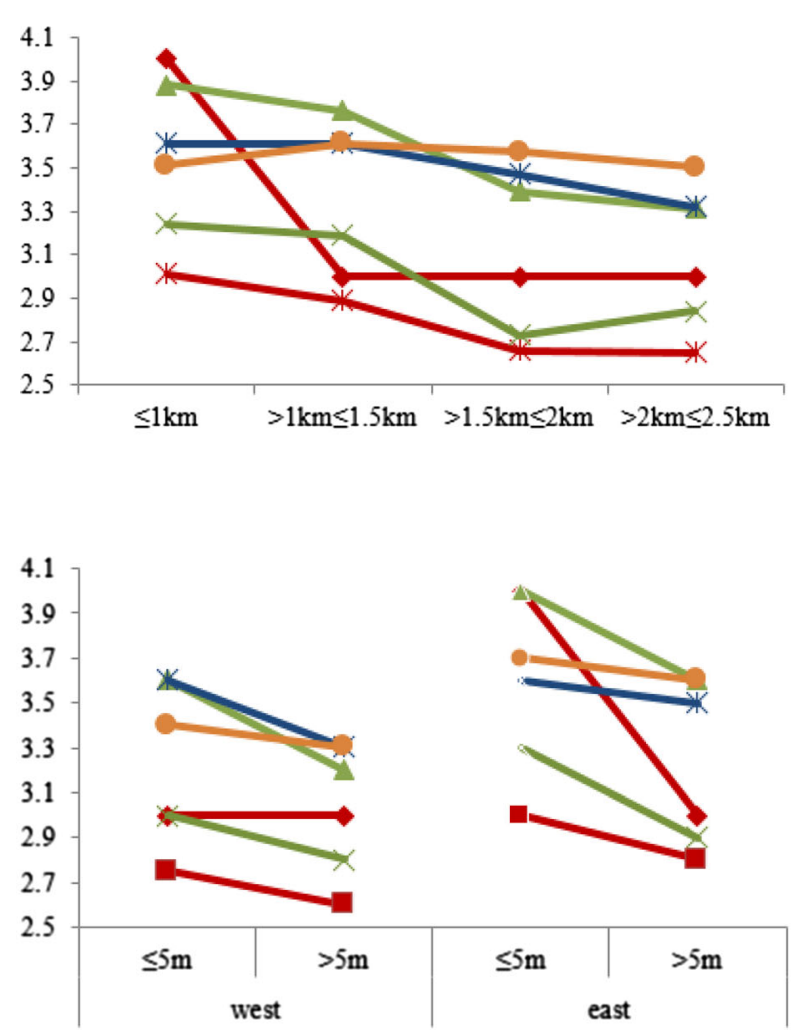

-Perceived likelihood of Natech before the GEJET

Perceived severity of Natech before the GEJET

-Perceived likelihood of Natech just after the earthquake shaking

$\because$ Perceived severity of Natech just after the earthquake shaking

- Perceived severity when the Natech occurred

- Perceived severity when received Natech evacuation order

Perceived likelihood of Natech
before the GEJET
- Perceived severity of Natech
before the GEJET
Perceived likelihood of Natech
just after the earthquake shaking
- Perceived severity of Natech just
after the earthquake shaking
- Perceived severity when the
Natech occurred
- Perceived severity when received
Natech evacuation order

Natech hazard. The results are shown in Fig. 7. We used two-between-one-within ANOVA tests to find the significance. Between subjects were direction (west and east) and elevation $(\leq 5$, and $>5 \mathrm{~m})$, and within subjects were risk perceptions in four time periods (before the quake, just after the earthquake shaking, when respondents perceived the Natech occurrence, and when they received a Natech evacuation order). Results show that households living in the east side of the Natech hazard perceived significantly higher Natech risk in terms of likelihood (before the quake and just after the earthquake shaking) ( $F$ $\left.(1,441)=18.67, p<0.01, \eta^{2}=0.04\right)$. Those respondents living at a lower elevation $(\leq 5 \mathrm{~m})$ also perceived higher Natech risk in terms of likelihood (before the quake and just after the earthquake shaking) than those at a higher elevation $(>5 \mathrm{~m})\left(F(1,441)=8.44, p=0.008, \eta^{2}=0.02\right)$. However, respondents' perceived that Natech risk in terms of its severity (during the four examined time periods) was not significantly different according to the direction and elevation.

\subsection{Behavioral Response}

Respondents were specially asked to indicate what they did to protect themselves or family members after perceiving the Natech accident by themselves (through its environmental cues such as seeing the fire or smelling the smoke) or from the local government's warning. They were asked to select one or more of the following options: immediately evacuated, immediately prepared for evacuation, closed the windows and doors, tried to find more information (searched for information), got out of the house to see the accident situation (assessed situation), continued normal activities, and took other actions.
Fig. 8 Protective actions after perceiving the Natech accident $(N=484)$

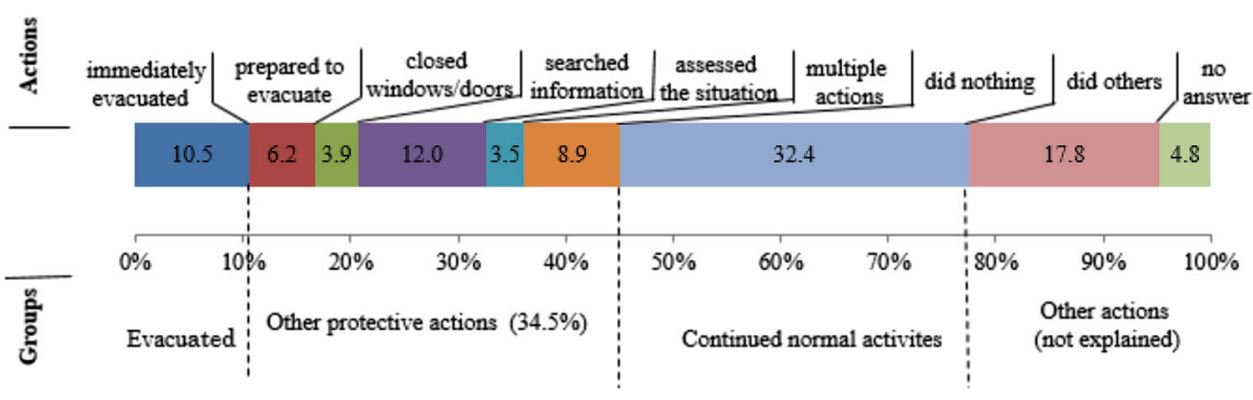


Table 3 Number (percent) of respondents according to evacuation timing and reasons for evacuating

\begin{tabular}{|c|c|c|c|c|c|c|}
\hline & \multirow{2}{*}{$\begin{array}{l}\text { Immediate } \\
\text { evacuation } \\
\text { Immediately } \\
\text { evacuated }\end{array}$} & \multicolumn{4}{|c|}{ Delayed evacuation } & \multirow[t]{2}{*}{ Total } \\
\hline & & $\begin{array}{l}\text { Other protective } \\
\text { actions }\end{array}$ & $\begin{array}{l}\text { Continued normal } \\
\text { activites }\end{array}$ & $\begin{array}{l}\text { Took other } \\
\text { action }\end{array}$ & Unknown & \\
\hline Evacuated for the Natech & $51(55.4 \%)$ & $24(26.1 \%)$ & $12(13.0 \%)$ & $2(2.2 \%)$ & $3(3.3 \%)$ & $92(19.0 \%)$ \\
\hline $\begin{array}{l}\text { Evacuated for other } \\
\text { reasons }\end{array}$ & 0 & $79(35.6 \%)$ & $75(33.8 \%)$ & $55(24.8 \%)$ & $13(5.9 \%)$ & $\begin{array}{l}222 \\
\quad(45.9 \%)\end{array}$ \\
\hline Did not evacuate & 0 & $60(39.2 \%)$ & $66(43.1 \%)$ & $25(16.3 \%)$ & $2(1.3 \%)$ & $\begin{array}{l}153 \\
(31.6 \%)\end{array}$ \\
\hline Unknown & 0 & $4(23.5 \%)$ & $4(23.5 \%)$ & $4(23.5 \%)$ & $5(29.4 \%)$ & $17(3.5 \%)$ \\
\hline Total & $51(10.5 \%)$ & $167(34.5 \%)$ & $157(32.4 \%)$ & $86(17.8 \%)$ & $23(4.8 \%)$ & 484 \\
\hline
\end{tabular}

Figure 8 presents the protective actions taken by households after perceiving the Natech accident. For ease of analysis, the protective actions have been classified into four groups as shown at the bottom of the figure. These results show that more than a third of respondents continued normal activities when they perceived the Natech $(32.4 \%)$. Only $10.5 \%$ of respondents evacuated immediately, but $34.5 \%$ of them took other protective actions, such as prepared to evacuate or closed windows/doors, and so on. Respondents who indicated they evacuated immediately and adopted other protective actions at the same time (for example, close the windows/doors) were classified as "evacuated."

Even though a relatively small group of households evacuated immediately after perceiving the Natech danger, some of them evacuated later. Table 3 presents households' evacuations for the Natech accident according to evacuation timing for the four groups as shown in Fig. 8. As shown in Table 3, of the 484 respondents, 92 (19.0\%) left home because of the Natech accident; whereas 222 (45.9\%) evacuated for reasons such as the earthquake, tsunami, and so on. Furthermore, there were 153 (31.6\%) respondents who did not evacuate. Among the Natech evacuees, $55.4 \%$ of them evacuated immediately after perceiving the Natech accident and $26.1 \%$ of them adopted other protective measures before evacuating. Moreover, $15.2 \%$ of them also evacuated even though they initially continued normal activities $(13.0 \%)$ or did something else $(2.2 \%)$ before evacuating. A high percentage $(39.2 \%)$ of households did not evacuate, but sheltered at home by adopting other protective actions.

Households' behavioral responses to the Natech accident may be affected by their locations and risk perceptions. For example, respondents living near the industrial park may have perceived the Natech earlier and considered it serious, which may have motivated them to evacuate immediately. In comparison, those living at greater distances from the industrial park may have perceived the Natech late and paid less attention to it. Thus, they may have chosen to shelter at home by adopting other protective actions, such as search for more information or prepare to evacuate, or even to do nothing.

\subsection{Correlates of Risk Perception}

The relationship between risk perceptions and location and demographic characteristics in four time periods (before the quake, just after the earthquake shaking, when respondents perceived the Natech occurrence, and when they received the Natech evacuation order) was examined. Geographic variables included coded variables corresponding to the distance between the house and the refinery $(1=\leq 1 \mathrm{~km}, 2=>1 \mathrm{~km}$ and $\leq 1.5 \mathrm{~km}, 3=>1.5 \mathrm{~km}$ and $\leq 2 \mathrm{~km}, 4=>2 \mathrm{~km}$ and $\leq 2.5 \mathrm{~km}$ ), the location of the house with respect to the industrial park ( $1=$ east, $0=$ west $)$, and the average elevation of each area. Demographic characteristics included gender $(0=$ male, $1=$ female $)$, age, household size ( $1=$ single, $2=$ couples, $3=$ two generations, $4=$ three generations, $5=$ more than three generations), and residence length $(1=10$ years or less, $2=$ more than $10-20$ years, $3=$ more than $20-30$ years, $4=$ more than 30-40 years, $5=$ more than 40 years).

As indicated in Table 4, respondents' risk perceptions were associated with their locations. Specifically, significant negative correlations were found between distance to the industrial park and the risk perceptions in three time periods. This indicates that households' risk perceptions before the quake, just after the earthquake shaking, and when they perceived the Natech accident decreased with the distance to the Natech hazards. Furthermore, we found that households living to the east of the industrial park felt that a Natech accident was more likely to threaten their lives or property before the quake $(r=0.17)$ and just after the earthquake shaking $(r=0.16)$. They also felt more threatened by the Natech accident when they received its linked evacuation order $(r=0.16)$. In addition, the results indicate that households living in high places felt less 


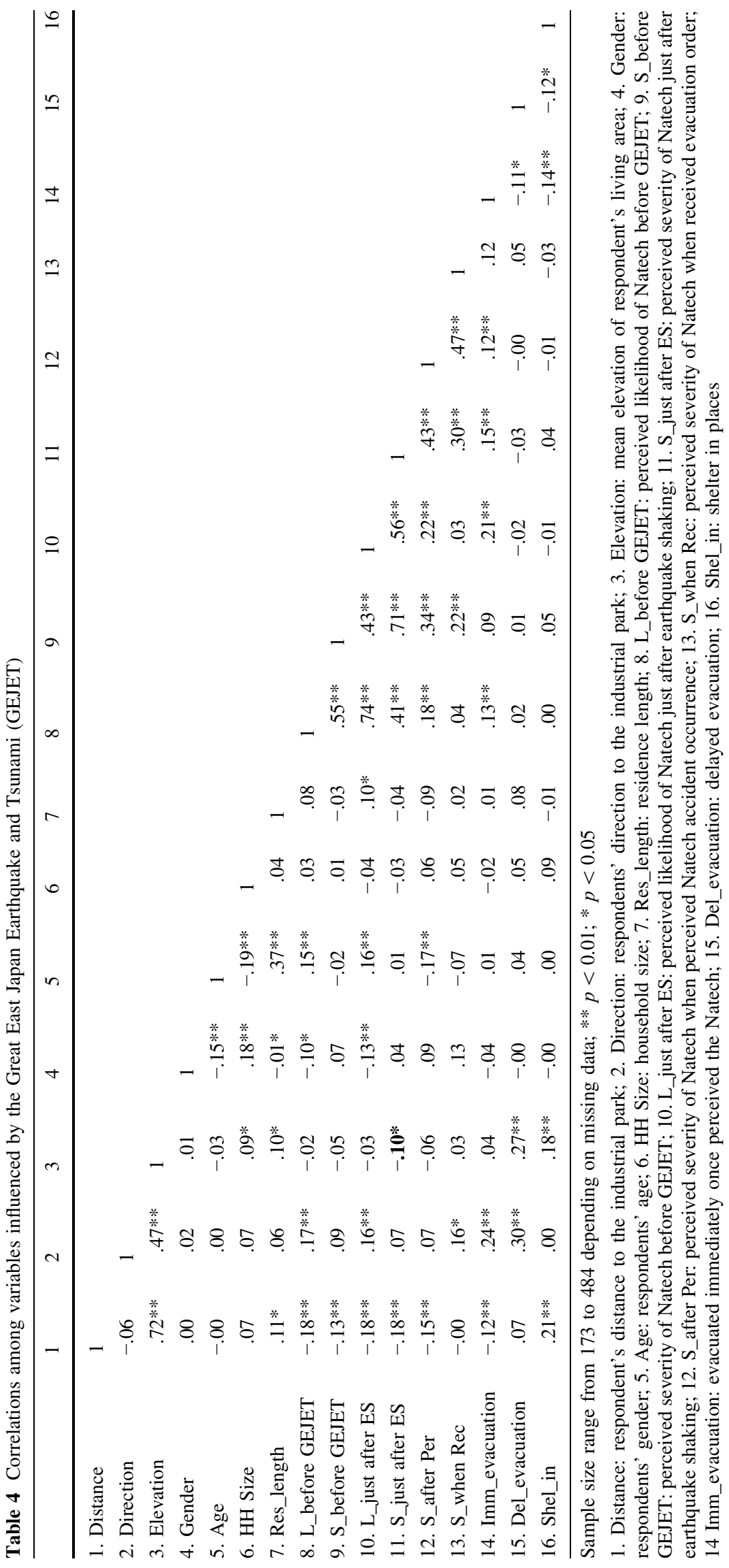


Table 5 Prediction of immediate evacuation in the Great East Japan Earthquake and Tsunami event (GEJET)

\begin{tabular}{lclr}
\hline Variables & $B$ & Standard error & Exp $(B)$ \\
\hline Distance & 0.13 & 0.66 & 1.14 \\
Direction & $2.44^{*}$ & 1.16 & 11.41 \\
Elevation & -0.06 & 0.13 & 0.94 \\
L_before GEJET & 0.49 & 0.45 & 1.64 \\
S_before GEJET & 0.20 & 0.41 & 1.23 \\
L_just after ES & 0.52 & 0.45 & 1.69 \\
S_just after ES & -0.48 & 0.50 & 0.62 \\
S_after Per & $1.77^{*}$ & 0.83 & 5.89 \\
S_when Rec & -0.37 & 0.58 & 0.69 \\
Female & -.003 & 0.57 & 0.10 \\
Age & 0.04 & 0.03 & 1.04 \\
HH Size & 0.37 & 0.29 & 1.44 \\
Res_length & 0.04 & 0.16 & 1.04 \\
Constant & $-15.33^{* *}$ & 4.50 & 0.00 \\
$X^{2}$ & $27.86^{* *}$ & & \\
$d f$ & 13 & & \\
Nagelkerke $R^{2}$ & 0.32 & & \\
\hline
\end{tabular}

$* * p<0.01 ; * p<0.05$

threatened by the Natech accident just after the earthquake shaking $(r=-0.10)$.

Gender and age were found to be correlated with risk perception. Specifically, men $(r=-0.10 /-0.13)$ and older people $(r=0.15 / 0.16)$ were more likely to regard a Natech accident as a threat to their lives or property before the quake and just after the earthquake shaking. However, younger households felt more threaten by the Natech accident when they perceived its occurrence $(r=-0.17)$. In addition, the results also show that long-term residents had higher risk perception levels in terms of perceived likelihood just after the earthquake shaking $(r=0.10)$.

\subsection{Correlates of Protective Actions}

We examined the correlations between location, demographic characteristics, risk perception, and three types of protective actions: immediate evacuation, delayed evacuation, and shelter in place. Based on the results in Table 4, respondents who indicated they evacuated immediately after perceiving the Natech were recorded as $1=$ yes, others were $0=$ no. Those who delayed evacuations were recorded as $1=$ yes, others were $0=$ no. Finally, those who sheltered in place were recorded as $1=$ yes, others were $0=$ no.

We found that households' evacuation behavior differed significantly by locations. Specifically, households living in proximity to the Natech accident were more likely to evacuate at once when they perceived its threat $(r=-0.12)$, whereas those living further away tended to shelter in place $(r=0.21)$. Moreover, those at a higher elevation were also prone to delay their evacuation $(r=0.27)$ and shelter in place $(r=0.18)$. Furthermore, those living to the east side of the industrial park were more likely to evacuate immediately $(r=0.23)$ and, even for those did not evacuate initially were more likely to evacuate than those in the west side $(r=0.32)$ some time later.

Households were also more likely to evacuate after perceiving the Natech accident if: (1) they thought it very likely that their lives or property were threatened by the Natech accident before the Great East Japan Earthquake and Tsunami and just after the earthquake shaking; and (2) they considered that the Natech would affect their lives and property to a very great extent just after the earthquake shaking and when they perceived it.

\subsection{Prediction of Immediate Evacuation}

A logistic regression was conducted to predict households' immediate evacuation behavior using geographic, risk perception, and demographic variables. As indicated in Table 5, predictor variables account for 32\% (Nagelkerke$R^{2}$ ) of the variance in predicting evacuation after perceiving the Natech. Coefficients on two variables of interest are statistically significant. The first significant predictor indicates that people living to the east of the industrial park were approximately 12 times $(\exp (B)=11.41)$ more likely to evacuate when they perceived the Natech accident. The second significant predictor indicates that for each additional one-point increase in severity ratings when households perceived the Natech accident, they were 5.89 times $(\exp (B)=5.89)$ more likely to evacuate.

\section{Discussion}

In response to the first research question concerning Natech accident risk perception change through an evacuation process, this article analyzed the change of household risk perception during the Natech accident evacuation. Recognizing changes in risk perception can assist in understanding when people will take protective actions such as evacuation (Lindell and Prater 2012). This is important to understand the role that risk perception plays in triggering multiple evacuations. Previous studies have shown that risk perception was strongly related to evacuation decisions (Baker 1991; Huang et al. 2012; Lindell et al. 2015). But emergency managers also need to know when household evacuation may begin (for example, evacuation based on a person's own judgment, after an evacuation order) in order to allocate emergency resources or start special protective plans. This study confirms and extends the former finding 
that higher risk perception levels occurred while evacuees were staying at evacuation shelters (Siebeneck and Cova 2012). The results of this study show that there was higher household risk perception in terms of perceived severity of the Natech accident: when they perceived the Natech accident, when they received evacuation order, and while they were staying at the first or second evacuation shelter.

Concerning the second research question (What protective actions did households take in response to the Natech accident?), our results show that only $10.4 \%$ of respondents evacuated immediately after perceiving the Natech threat, whereas $34.5 \%$ of them adopted other protective actions instead. This finding is consistent with an earlier study on households' immediate response to the 2009 American Samoa earthquake and tsunami (Lindell et al. 2015). The authors also found that people did not leave immediately after the earthquake shaking but attempted to obtain additional information, packed an emergency kit, or protected property. Searching for more information was also found to be one of the primary protective actions in this study (12\% of the respondents tried to do so). Furthermore, a relatively large group of respondents $(32.4 \%)$ continued their normal activities after perceiving the Natech accident. Not being familiar with the Natech phenomenon or not receiving the Natech evacuation order may be the reason for this.

The third objective was to explore whether households in different locations perceived different Natech risks and adopted different protective actions. Results that show risk perception levels decreasing with distance to the Natech accident are consistent with the findings in other studies concerning hurricane evacuation (Baker 1991; Lindell and Prater 2004). Furthermore, we also found that respondents living to the east of the industrial park felt they were more likely to be affected by the Natech accident before the quake, and just after the earthquake shaking, than those living to the west. Based on data from the Japan Meteorological Agency (JMA), the annual average wind direction of the investigated area was northwest (JMA 2014). This indicates that households living in the eastside may have been more worried about their safety because they could smell or see the smoke driven by the wind. To understand why households on the east side believed the Natech could

Table 6 Wind direction, duration, and speed during the Natech accident. Source JMA (2014)

\begin{tabular}{lll}
\hline Wind direction & Duration $(\mathrm{h})$ & Average wind speed $(\mathrm{m} / \mathrm{s})$ \\
\hline East & 58 & 2.72 \\
West & 24 & 1.90 \\
Others & 9 & 2.23
\end{tabular}

From 9 p.m. 11 March to 15 p.m. 15 March, $91 \mathrm{~h}$ affect their lives or property to a very great extent after receiving the evacuation order, we need further analysis. One possibility may be the warning message. Lindell and Perry state that the warning source, warning channels, and message content stimulate recipients to establish a threat belief in and response to the disaster (Lindell and Prater 2004). Further research could examine the way that these three components influence risk perception when households received the Natech evacuation order.

Concerning protective actions, we found that households living close to the industrial park were more likely to evacuate immediately after perceiving the Natech accident, whereas those living further away tended to shelter at home. According to Huang et al. (2012) this is because residents who are closer to the hazards are more likely to personalize the risk by anticipating more severe impacts from those threats.

Our study also indicates that households located to the leeward side (east) of the industrial park were more likely to evacuate immediately when they perceived the Natech threat or evacuated later if needed. This may be due to the wind direction, which was predominantly from west to east. Table 6 shows that during the duration $(91 \mathrm{~h})$ of the Natech accident, the wind direction was east for a period of $58 \mathrm{~h}$ with an average wind speed of $2.72 \mathrm{~m} / \mathrm{s}$. This indicates that more households to the east side may have evacuated because they smelled the smoke driven by the wind. This is good news because those living in that direction may be more likely to be affected by the flames or toxic vapors resulted from fires or hazardous material releases carried by the wind. However, residents on the windward side may be at risk of explosion hazards and thus should also be aware of the potential dangers and the actions that they should take to protect themselves. Therefore measures should be also taken to increase their Natech-related knowledge and disaster preparedness.

The examination of the relationship between risk perception and evacuation behavior by both correlation and regression analysis suggests that households were more likely to evacuate immediately if they felt their lives or property would be impacted by the Natech accident to a very great extent when they perceived its occurrence.

Our study results are similar to the findings of other scholars that show that demographic variables have weak and inconsistent correlations with risk perception and protective responses (Baker 1991; Lindell and Perry 2000; Steinberg et al. 2004; Lindell et al. 2015). For example, our results regarding gender are inconsistent with prior research, which found that women perceived disaster events or threats as more severe and risky than men (Bateman and Edwards 2002). However, we found that men were more likely to consider a Natech accident as a threat to their lives or property in two time periods: before 
the Great East Japan Earthquake and Tsunami and just after the earthquake shaking. Age may play a role in this result, because older respondents were also found to be more likely to worry about their lives or property being affected by a Natech accident in the same time periods. Thus, further studies should be conducted to analyze the risk perception of subgroups such as older women or younger men. Moreover, age was not a persistent determinant of risk perception, for after perceiving the Natech accident, the older respondents conversely regarded the Natech as a less severe threat.

\section{Study Limitations}

This study has some limitations. First, data collection was carried out about 3 years after the Natech accident occurred during the Great East Japan Earthquake and Tsunami. This raises questions regarding respondents' answers concerning their perceived risks at the time of the disaster. Lindell et al. (2015) found that people tend to have good memories of events that are personally relevant to them. During our interviews with residents in the affected area to test the survey questionnaires, many residents described their feeling and actions during the Natech accident clearly. The earthquake and tsunami and the Natech accident that followed comprised a devastating event that has marked residents personally and significantly. Thus, it appears to be reasonable to draw conclusions based on the collected data.

Second, although this study has examined the effects of three significant factors (risk perception, location, and demographic characteristics) on household behavioral response to the Natech threat, some bias may have been introduced because the respondents' house damage state was not discussed. Severely damaged houses may have forced people to adopt immediate protective actions, such as evacuate immediately. Thus, further studies should consider this potentially influential factor.

Another limitation comes from potential sample bias. Information concerning residents who moved away from the surveyed areas is unknown. This group of residents may have been severely affected by the Natech accident. Their absence from the study's data base could have introduced a bias into the study results.

\section{Conclusion}

This study has presented the results of a random household mail survey on risk perception and behavioral responses to a Natech accident experienced at an industrial park in Sendai, Japan, after the Great East Japan Earthquake and Tsunami of 2011. Interestingly, the evacuation process that followed the earthquake, tsunami, and Natech accident involved multiple evacuations. The study showed that Natech risk perception changed throughout the evacuation process. Comparatively low mean risk perception levels (in terms of perceived likelihood) occurred before the earthquake. Higher mean risk perception levels (in terms of perceived severity) occurred when households perceived the Natech accident, especially while they were staying at either the first or second evacuation shelter, and when they received the actual Natech evacuation order. Furthermore, the study confirmed that risk perception has a significant and positive effect on evacuation behavior. Thus, finding ways to improve households' risk perception concerning Natech hazards may lead to increased evacuation for any future Natech accident. This finding is important because it confirms the conclusion of previous research that expected personal impacts are strong motivation for a person's protective actions (Fitzpatrick and Mileti 1991; Sorensen 2000; Huang et al. 2012; Lindell and Prater 2012).

The study showed that almost $30 \%$ of respondents evacuated at least once for the Natech accident. But the majority did not evacuate immediately, and instead adopted other protective actions when they perceived the Natech threat. Inside this group, $12 \%$ of respondents tried to search for more information. According to Sorensen, the single most important factor in determining when people will leave is when they are informed about the danger (Sorensen 1991). The information may concern the certainty, severity, and immediacy of the threat, and identify logistical support for protective actions such as suitable evacuation routes, destinations, and modes of transportation, and so on (Lindell and Prater 2012). Therefore, local government officials and industrial facility operators should provide adequate and timely information and instructions to residents about protective measures at the time of an evacuation order. Prior natural and technological disaster preparedness planning is needed to insure that residents in potentially impacted areas will know what protective actions they can take in case of a Natech accident. Unfortunately, there is very little information currently provided to residents living near industrial parks in Japan concerning hazards that result from the handling of hazardous materials and the measures citizens can take to protect themselves in the event of a chemical accident, and even less concerning the chemical accidents triggered by an earthquake and/or tsunami.

Future studies should pay special attention to the need for multiple evacuations. It is not clear if the high number of Sendai evacuations can be expected during every future Natech accident. Studies that investigate how common it is for households to evacuate multiple times and the reasons for the multiple evacuations should be carried out. Emphasis should also be placed on identifying the specific 
threats present during the multiple evacuations and how emergency mangers can effectively manage the multiple evacuation process. In addition, studies should also examine the return process after a Natech accident. Because Natech accidents are associated with hazardous or toxic materials releases, it is challenging for local authorities as well as evacuees to know when it is safe to return. The findings here presented on risk perception and behavioral responses of households in Sendai, when faced with a Natech accident during the Great East Japan Earthquake and Tsunami, provide important insight for future disaster preparedness planning in Japan as well as in other countries.

Open Access This article is distributed under the terms of the Creative Commons Attribution 4.0 International License (http://crea tivecommons.org/licenses/by/4.0/), which permits unrestricted use, distribution, and reproduction in any medium, provided you give appropriate credit to the original author(s) and the source, provide a link to the Creative Commons license, and indicate if changes were made.

\section{References}

Baker, E.J. 1991. Hurricane evacuation behavior. International Journal of Mass Emergencies and Disasters 9(2): 287-310.

Bateman, J.M., and B. Edwards. 2002. Gender and evacuation: A closer look at why women are more likely to evacuate for hurricanes. Natural Hazards Review 3(3): 107-117.

Cozzani, V., M. Campedel, E. Renni, and E. Krausmann. 2010. Industrial accidents triggered by flood events: Analysis of past accidents. Journal of Hazardous Materials 175(1-3): 501-509.

Cruz, A.M., and E. Krausmann. 2008. Damage to offshore oil and gas facilities following hurricanes Katrina and Rita: An overview. Journal of Loss Prevention in the Process Industries 21(6): 620626.

Dash, N., and H. Gladwin. 2007. Evacuation decision making and behavioral responses: Individual and household. Natural Hazards Review 8(3): 69-77.

Fitzpatrick, C., and D.S. Mileti. 1991. Motivating public evacuation. International Journal of Mass Emergencies and Disasters 9(2): $137-152$

Huang, S.-K., M.K. Lindell, C.S. Prater, H.-C. Wu, and L.K. Siebeneck. 2012. Household evacuation decision making in response to Hurricane Ike. Natural Hazards Review 13(4): 283 296.

JMA (Japan Meteorological Agency). 2014. Web site. http://www. data.jma.go.jp/obd/stats/etrn/view/10min_a1.php?prec_no=34\&block_ no $=1030 \&$ year $=2011 \&$ month $=3 \&$ day $=11 \&$ view. Accessed 11 Aug 2014 (in Japanese).

Kellens, W., R. Zaalberg, T. Neutens, W. Vanneuville, and P. De Maeyer. 2011. An analysis of the public perception of flood risk on the Belgian coast. Risk Analysis 31(7): 1055-1068.

Krausmann, E., and D. Baranzini. 2012. Natech risk reduction in the European Union. Journal of Risk Research 15(8): 1027-1047.

Krausmann, E., and A.M. Cruz. 2013. Impact of the 11 March 2011, Great East Japan earthquake and tsunami on the chemical industry. Natural Hazards 67(2): 811-828.

Krausmann, E., E. Renni, M. Campedel, and V. Cozzani. 2011. Industrial accidents triggered by earthquakes, floods and lightning: Lessons learned from a database analysis. Natural Hazards 59(1): 285-300.

Lin, C.-C., L.K. Siebeneck, M.K. Lindell, C.S. Prater, H.-C. Wu, and S.-k. Huang. 2014. Evacuees' information sources and reentry decision making in the aftermath of Hurricane Ike. Natural Hazards 70(1): 865-882.

Lindell, M.K. 2012. Response to environmental disasters. In The Oxford handbook of environmental and conservation psychology, ed. S.D. Clayton, 391-413. New York: Oxford University Press.

Lindell, M.K. 2013. North American cities at risk: Household responses to environmental hazards. In Cities at risk: Living with perils in the 21th century, ed. H. Joffe, T. Rossetto, and J. Adams, 109-130. Dordrecht: Springer.

Lindell, M.K., and T.C. Earle. 1983. How close is close enough: Public perceptions of the risks of industrial facilities. Risk Analysis 3(4): 245-253.

Lindell, M.K., and R.W. Perry. 1997. Hazardous materials releases in the Northridge earthquake: Implications for seismic risk assessment. Risk Analysis 17(2): 147-156.

Lindell, M.K., and R.W. Perry. 2000. Household adjustment to earthquake hazard a review of research. Environment and Behavior 32(4): 461-501.

Lindell, M.K., and C.S. Prater. 2004. Communicating environmental risk in multiethnic communities. Thousand Oaks, CA: Sage.

Lindell, M.K., and C.S. Prater. 2012. The protective action decision model: Theoretical modifications and additional evidence. Risk Analysis 32(4): 616-632.

Lindell, M.K., J.C. Lu, and C.S Prater. 2005. Household decision making and evacuation in response to Hurricane Lili. Natural Hazard Review 6(4): 171-179.

Lindell, M.K., C.S. Prater, C.E. Gregg, E.J. Apatu, S.-K. Huang, and H.C. Wu. 2015. Households' immediate responses to the 2009 American Samoa Earthquake and Tsunami. International Journal of Disaster Risk Reduction 12: 328-340.

Luathep, P., A. Suwansunthon, S. Sutthiphan, and P. Taneerananon. 2013. Flood evacuation behavior analysis in urban areas. Journal of the Eastern Asia Society for Transportation Studies 10: 178-195.

Mileti, D.S., and P.W. O'Brien. 1992. Warnings during disaster: Normalizing communicated risk. Social Problems 39(1): 40-57.

Mileti, D.S., and L. Peek. 2000. The social psychology of public response to warnings of a nuclear power plant accident. Journal of Hazardous Materials 75(2-3): 181-194.

Mimura, N., K. Yasuhara, S. Kawagoe, H. Yokoki, and S. Kazama. 2011. Damage from the Great East Japan Earthquake and Tsunami-A quick report. Mitigation and Adaptation Strategies for Global Change 16(7): 803-818.

Mitchell, J.T., A.S. Edmonds, S.L. Cutter, M.C. Schmidtlein, R.L. McCarn, M.E. Hodgson, and S. Duhé. 2005. Evacuation behavior in response to the Graniteville, South Carolina, Chlorine Spill. Quick Response Research Report 178, University of Sourth Carolina.

MLITT (Ministry of Land, Infrastructure, Transport and Tourism). 2014. The 2011 Great East Japan Earthquake Disaster survey results (first report). http://www.mlit.go.jp/common/000162533. pdf. Accessed 10 Oct 2014 (in Japanese).

Nishi, H. 2012. Damage of hazmat facilities due to fires and tsunami. In Proceeding of the international symposium on engineering lessons learnt from the 2011 Great East Japan Earthquake, 1-2 March 2012, Tokyo, Japan.

NPA (National Police Agency). 2014. Damage situation and police measures of the 2011 Great East Japan Earthquake. https://www. npa.go.jp/archive/keibi/biki/higaijokyo.pdf. Accessed 20 Dec 2014 (in Japanese).

Peacock, W.G., S.D. Brody, and W. Highfield. 2005. Hurricane risk perceptions among Florida's single family homeowners. Landscape and Urban Planning 73(2-3): 120-135. 
Riad, J.K., F.H. Norris, and R.B. Ruback. 1999. Predicting evacuation in two major disasters: Risk perception, social influence, and access to Resources. Journal of Applied Social Psychology 29(5): 918-934.

Sengul, H., N. Santella, L.J. Steinberg, and A.M. Cruz. 2012. Analysis of hazardous material releases due to natural hazards in the United States. Disasters 36(4): 723-743.

Shichigahama. 2012. The documentary of Schichigahama town during the Great East Japan Earthquake and Tsunami. https:// www.shichigahama.com/benricho/joho/d89-010.html. Accessed 26 Apr 2016 (in Japanese).

Showalter, P.S., and M.F. Myers. 1992. Natural disasters as the cause of technological emergencies: A review of the decade, 1980 1989. Natural Hazards Research and Applications Information Center, Institute of Behavioral Science, University of Colorado.

Siebeneck, L.K., and T.J. Cova. 2012. Spatial and temporal variation in evacuee risk perception throughout the evacuation and returnentry process. Risk Analysis 32(9): 1468-1480.

Solis, D., M. Thomas, and D. Letson. 2009. Determinants of household hurricane evacuation choice in Florida. Presentation at the Southern Agricultural Economics Association Annual Meeting, 31 January-3 February 2009, Atlanta, Georgia.

Sorensen, J.H. 1991. When shall we leave? Factors affecting the timing of evacuation departures. International Journal of Mass Emergencies and Disasters 9(2): 153-165.

Sorensen, J.H. 2000. Hazard warning systems: Review of 20 years of process. Natural Hazard Review 1(2): 119-125.

Sorensen, J.H., and B.V. Sorensen. 2007. Community process: Warning and evacuation. In Handbook for disaster research, ed. H. Rodriguez, E. Quarantelli, and R. Dynes, 183-199. New York: Springer.

Steinberg, L.J., V. Basolo, R. Burby, J.N. Levine, and A. Maria Cruz. 2004. Joint seismic and technological disasters: Possible impacts and community preparedness in an urban setting. Natural Hazards Review 5(4): 159-169.

Steinberg, L.J., H. Segul, and A.M Cruz. 2008. Natech risk and management: An assessment of the state of the art. Natural Hazards 46(2): 143-152.

Stern, P.C., T. Dietz, and L. Kalof. 1993. Value orientations, gender, and environmental concern. Environment and Behavior 25: 322 348.

Tagajo. 2012. The documentary of damages in Tagajo City caused by the Great East Japan Earthquake and Tsunami. http://www.city. tagajo.miyagi.jp/saigai/book/_SWF_Window.html?pagecode= 55. Accessed 16 Aug 2014 (in Japanese).

Tierney, K.J., M.K. Lindell, and R.W. Perry (eds.). 2001. Facing the unexpected: Disaster preparedness and response in the United States. Washington, DC: Joseph Henry Press.

USGS (U.S. Geological Survey). 2014. Historic world earthquake. http://earthquake.usgs.gov/earthquakes/world/historical_mag.php. Accessed 20 Dec 2014.

Yamagochi, K. 2012. Fire-fighting activities of Sendai JX refinery in Tohoku Earthquake. Safety \& Tomorrow 144: 9-15. http://www. khk-syoubou.or.jp/pdf/guide/magazine/144/.../144_9.pdf. Accessed 12 Mar 2016 (in Japanese).

Zama, S., H. Nishi, K. Hatayama, M. Yamada, H. Yoshihara, and Y. Ogawa. 2012. On damage of oil storage tanks due to the 2011 off the Pacific Coast of Tohoku Earthquake (Mw9.0), Japan. In Proceedings of the 15th World Conference on Earthquake Engineering (WCEE), 24-28 September, Lisbon, Portugal. http://www.iitk.ac.in/nicee/wcee/article/WCEE2012_0238.pdf. Accessed 15 Aug 2014.

Zelinski, W., and A. Kisinski. 1991. Emergency evacuation of cities. Savage, MD: Bowman \& Littlefield. 